\title{
Optical properties of size fractions of suspended particulate matter in littoral waters of Québec
}

\author{
Gholamreza Mohammadpour ${ }^{1}$, Jean-Pierre Gagné ${ }^{1}$, Pierre Larouche ${ }^{2}$, and Martin A. Montes-Hugo ${ }^{1}$ \\ ${ }^{1}$ Institut des Sciences de la Mer de Rimouski, 310 Alleé des Ursulines, Office P-216, Rimouski, Québec, G5L 3A1, Canada \\ ${ }^{2}$ Institut Maurice-Lamontagne, Pêches et Océans Canada, Mont-Joli, Québec, G5H 3Z4, Canada \\ Correspondence to: Martin A. Montes-Hugo (martinalejandro_montes@uqar.ca)
}

Received: 25 April 2017 - Discussion started: 1 June 2017

Revised: 19 October 2017 - Accepted: 24 October 2017 - Published: 29 November 2017

\begin{abstract}
Mass-specific absorption $\left(a_{i}{ }^{*}(\lambda)\right)$ and scattering $\left(b_{i}^{*}(\lambda)\right)$ coefficients were derived for four size fractions ( $i=0.2-0.4,0.4-0.7,0.7-10$, and $>10 \mu \mathrm{m}, \lambda=$ wavelength in $\mathrm{nm}$ ) of suspended particulate matter (SPM) and with samples obtained from surface waters (i.e., 0-2 $\mathrm{m}$ depth) of the Saint Lawrence Estuary and Saguenay Fjord (SLE-SF) during June of 2013. For the visible-near-infrared spectral range (i.e., $\lambda=400-710 \mathrm{~nm}$ ), mass-specific absorption coefficients of total SPM (i.e., particulates $>0.2 \mu \mathrm{m}$ ) (hereafter $a_{\text {SPM }}{ }^{*}$ ) had low values (e.g., $<0.01 \mathrm{~m}^{2} \mathrm{~g}^{-1}$ at $\lambda=440 \mathrm{~nm}$ ) in areas of the lower estuary dominated by particle assemblages with relatively large mean grain size and high particulate organic carbon and chlorophyll $a$ per unit of mass of SPM. Conversely, largest $a_{\mathrm{SPM}}{ }^{*}$ values (i.e., $>0.05 \mathrm{~m}^{2} \mathrm{~g}^{-1}$ at $\lambda=440 \mathrm{~nm}$ ) corresponded with locations of the upper estuary and SF where particulates were mineral-rich and/or their mean diameter was relatively small. The variability of two optical proxies (the spectral slope of particulate beam attenuation coefficient and the mass-specific particulate absorption coefficient, hereafter $\gamma$ and Svis, respectively) with respect to changes in particle size distribution (PSD) and chemical composition was also examined. The slope of the PSD was correlated with $b_{i}{ }^{*}(550)$ (Spearman rank correlation coefficient $\rho_{\mathrm{s}}$ up to 0.37$)$ and $a_{i}{ }^{*}(440)$ estimates ( $\rho_{\mathrm{s}}$ up to 0.32 ) in a comparable way. Conversely, the contribution of particulate inorganic matter to total mass of SPM $\left(F_{\text {SPM }}{ }^{\text {PIM }}\right)$ had a stronger correlation with $a_{i}{ }^{*}$ coefficients at a wavelength of $440 \mathrm{~nm}$ ( $\rho_{\mathrm{S}}$ up to 0.50 ). The magnitude of $\gamma$ was positively related to $F_{\mathrm{SPM}}{ }^{i}$ or the contribution of size fraction $i$ to the total mass of SPM ( $\rho_{\mathrm{s}}$ up to 0.53 for $i=0.2-0.4 \mu \mathrm{m}$ ). Also, the relation between $\gamma$ and $F_{\mathrm{SPM}}{ }^{\mathrm{PIM}}$ variability was secondary $\left(\rho_{\mathrm{s}}=-0.34, P>0.05\right)$. Lastly, the magnitude of
\end{abstract}

Svis was inversely correlated with $a_{\mathrm{SPM}}{ }^{*}(440)\left(\rho_{\mathrm{S}}=-0.55\right.$, $P=0.04)$ and $F_{\mathrm{SPM}}{ }^{\mathrm{PIM}}\left(\rho_{\mathrm{s}}=-0.62, P=0.018\right)$ in sampling locations with a larger marine influence (i.e., lower estuary).

\section{Introduction}

The distribution of suspended particulate matter (SPM) (Table 1) in coastal and estuarine environments has a major influence on biogeochemical processes (e.g., phytoplankton blooms) (Guinder et al., 2009), ecosystem structure (e.g., food web) (Dalu et al., 2016) and dispersion of pollutants (e.g., copper, mercury, polycyclic aromatic hydrocarbons) (Ma et al., 2002; Ramalhosa et al., 2005). Light absorption by suspended particulates is essential for several photochemical processes related to the carbon cycle (e.g., photosynthesis, production of dissolved inorganic and organic carbon) (Estapa et al., 2012). Lastly, the concentration of SPM is an important variable for modeling thermodynamic processes and computing heat budgets (Löptien and Meier, 2011) due to its influence on underwater light attenuation (Morel and Antoine, 1994; Devlin et al., 2008).

The spatial and temporal variability of suspended particulates is relatively high (i.e., > 100-fold) in littoral environments (Doxaran et al., 2002; Montes-Hugo and Mohammadpour, 2012). This represents a challenge for traditional methods of measuring SPM based on gravimetry (Strickland and Parson, 1972) as the analysis of a large number of samples is time-consuming and costly. Thus, these studies are commonly based on a relatively small dataset that may partially represent the in situ distributions of SPM. Due to these diffi- 
Table 1. Summary of abbreviations.

\begin{tabular}{|c|c|c|}
\hline Abbreviation & Definition & Unit \\
\hline SLE & St. Lawrence Estuary & \\
\hline UE & Upper estuary & \\
\hline SF & Saguenay Fjord & \\
\hline LE & Lower estuary & \\
\hline SPM & Suspended particulate matter & \\
\hline POM & Particulate organic matter & \\
\hline PIM & Particulate inorganic matter & \\
\hline PSD & Particle size distribution & \\
\hline$F_{\mathrm{SPM}}{ }^{i}$ & Contribution of size fraction $i$ to total mass of SPM & dimensionless \\
\hline$F_{\mathrm{SPM}^{j}}$ & Contribution of chemical fraction $j$ to total mass of SPM & dimensionless \\
\hline NAP & Non-algal particulates & \\
\hline CDOM & Chromophoric dissolved organic matter & \\
\hline$\lambda$ & Light wavelength & $\mathrm{nm}$ \\
\hline$a_{\mathrm{SPM}}$ & Absorption coefficient of total SPM & $\mathrm{m}^{-1}$ \\
\hline$b_{\mathrm{SPM}}$ & Scattering coefficient of total SPM & $\mathrm{m}^{-1}$ \\
\hline$c_{\mathrm{SPM}}$ & Particulate beam attenuation coefficient of total SPM & $\mathrm{m}^{-1}$ \\
\hline$a_{\mathrm{SPM}}{ }^{*}$ & Mass-specific absorption coefficient of total SPM & $\mathrm{m}^{2} \mathrm{~g}^{-1}$ \\
\hline$b_{\mathrm{SPM}}^{*}$ & Mass-specific scattering coefficient of total SPM & $\mathrm{m}^{2} \mathrm{~g}^{-1}$ \\
\hline$a_{i}^{*}$ & Mass-specific absorption coefficient of particle size fraction $i$ & $\mathrm{~m}^{2} \mathrm{~g}^{-1}$ \\
\hline$b_{i}^{*}$ & Mass-specific scattering coefficient of particle size fraction $i$ & $\mathrm{~m}^{2} \mathrm{~g}^{-1}$ \\
\hline$\xi$ & Slope of differential PSD & dimensionless \\
\hline$D$ & Diameter of a volume-equivalent sphere at midpoint of size class & $\mu \mathrm{m}$ \\
\hline$V(D)$ & Particle volume concentration per unit of volume at size class $D$ & $\mu \mathrm{LL}^{-1}$ \\
\hline$N(D)$ & Particle number concentration per unit of volume at size class $D$ & $m^{-3}$ \\
\hline$N^{\prime}(D)$ & Particle number density at size class $D$ & $\mathrm{~m}^{-3} \mu \mathrm{m}^{-1}$ \\
\hline$\gamma$ & Spectral slope of particulate beam attenuation coefficient & dimensionless \\
\hline Svis & $\begin{array}{l}\text { Spectral slope of mass-specific particulate absorption } \\
\text { coefficient within the visible spectral range }\end{array}$ & $\mathrm{nm}^{-1}$ \\
\hline
\end{tabular}

culties, several techniques have been developed for synoptic and large-scale mapping of SPM based on satellite-derived optical measurements (Doxaran et al., 2002; Miller and McKee, 2004; Montes-Hugo and Mohammadpour, 2012).

SPM is an unknown mixture of inorganic and organic matter that varies between locations and as a function of time due to diverse physical (e.g., tides) and biogeochemical (e.g., phytoplankton growth) factors (D'Sa and Ko, 2008; Eleveld et al., 2014). Thus, optical remote sensing algorithms for estimating SPM are region-specific and generally less accurate when applied to unknown littoral environments. This highlights the need for a better understanding of optical properties of SPM components that can be later used for estimating second-order attributes of SPM (i.e., chemical composition, size distribution) and designing more general remote sensing algorithms for retrieving total concentrations of particulates per unit of volume and across different water types.

In general, four techniques have been proposed for characterizing particle size distribution (PSD) and/or chemical composition of SPM based on optical parameters: (1) optical proxies (e.g., the spectral slope of the mass-specific particulate absorption coefficient, $\gamma$, the spectral slope of the partic- ulate absorption coefficient, Svis, and particulate backscattering/scattering ratio) (Boss et al., 2001; Twardowski et al., 2001; Loisel et al., 2006; Estapa et al., 2012), (2) massspecific optical coefficients (e.g., mass-specific particulate scattering, backscattering and beam attenuation coefficients) (Bowers et al., 2009; Neukermans et al., 2012), (3) particulate volume scattering functions (Zhang et al., 2014), and (4) water-leaving polarized reflectance (Loisel et al., 2008).

The Saint Lawrence Estuary (SLE) and the Saguenay Fjord (SF) constitute a large subarctic system characterized by relatively high concentrations of chromophoric dissolved organic matter (CDOM) (Nieke et al., 1997). The remote sensing of physical attributes of SPM (e.g., PSD) in these waters is crucial for studying regional climate effects on coastal erosion and occurrence of harmful algae blooms. However, in order to accomplish this task it is essential to know how mass-specific optical coefficients of suspended particulates are influenced by particle composition and size distribution changes. To our knowledge, mass-specific absorption and scattering coefficients of different SPM size fractions have never been reported in the literature even though it has a potential application in biogeo-optical modeling and biogeo- 
chemical studies regarding the dynamics of trace metals, sediment transport and primary productivity models.

This study has three main objectives: (1) to characterize the mass-specific absorption $\left(a_{i}{ }^{*}(\lambda)\right)$ and scattering $\left(b_{i}{ }^{*}(\lambda)\right)$ coefficients of four size fractions of SPM $(i=0.2-0.4,0.4-$ $0.7,0.7-10$, and $>10 \mu \mathrm{m}, \lambda=$ wavelength in $\mathrm{nm}$ ) at different locations of the SLE-SF during spring conditions, (2) to establish relationships between mass-specific optical coefficients and characteristics of particle assemblages related to PSD and mineral content of SPM, and (3) to examine the correlation between optical proxies $\gamma$ and Svis and variables linked to PSD and chemical composition of SPM.

This study is organized in three sections. In the first section, mass-specific absorption $\left(a_{\mathrm{SPM}}{ }^{*}\right)$ and scattering $\left(b_{\mathrm{SPM}^{*}}{ }^{*}\right)$ coefficients of total SPM (i.e., particulates larger than $0.2 \mu \mathrm{m})$ are calculated at different regions of the SLESF that are characterized by distinct particle assemblages and variable contributions of CDOM, non-algal particulates (NAP) and phytoplankton to light attenuation. In the second section, relationships between mass-specific optical coefficients of different SPM size fractions and parameters related to PSD and mineral content of suspended particulates are investigated. Lastly, in the third section, relationships between optical proxies $\gamma$ and Svis and particle chemical composition and PSD are analyzed.

\section{Data and methods}

\subsection{Study area}

The SLE can be divided in two main regions with contrasting biological productivity and bathymetry: the upper (UE) and the lower (LE) estuary (Levasseur et al., 1984). NAP and CDOM dominate the diffuse light attenuation of SLE waters (Nieke et al., 1997). This is partially related to the inflow of CDOM-rich and NAP-rich waters coming from the St. Lawrence River and Saguenay Fjord (Tremblay and Gagné, 2007; Xie et al., 2012). Unlike NAP and CDOM, contribution of phytoplankton to inherent optical properties increases towards the mouth of the SLE (Montes-Hugo and Mohammadpour, 2012; Xie et al., 2012).

The study of optical properties of suspended particulates in SLE waters began during the late 1980s. Babin et al. (1993) investigated the horizontal variability of the specific absorption coefficient of phytoplankton (i.e., absorption coefficient normalized by concentration of chlorophyll + phaeopigments) in surface waters during the summer of 1989 and 1990. Nieke et al. (1997) reported high values (up to $3 \mathrm{~m}^{-1}$ ) of particulate beam attenuation coefficients $\left(c_{\text {SPM }}\right)$ and inverse relationships between salinity, $c_{\text {SPM }}$, and CDOM absorption coefficients $\left(a_{\mathrm{CDOM}}\right)$ based on measurements done during summer of 1990. Larouche and BoyerVillemaire (2010) proposed remote sensing models for estimating particulate inorganic matter (PIM) in the SLE and the Gulf of Saint Lawrence. Xie et al. (2012) showed inverse relationships between salinity and absorption coefficients of NAP and highlighted the extremely high values of $a_{\mathrm{CDOM}}$ (i.e., up to $5.8 \mathrm{~m}^{-1}$ at $\lambda=412 \mathrm{~nm}$ ) along the Saguenay Fjord.

Historical studies performed during summer of 1975 suggest that size distribution of SPM differs between UE, LE and SF sub-regions (Poulet et al., 1986). Based on surface samples, Poulet et al. (1986) found a dominance of relatively "small-sized" (i.e., mode diameter $<10 \mu \mathrm{m}$ ) and relatively "large-sized" (i.e., mode diameter $>30 \mu \mathrm{m}$ ) particulates over the UE and the mouth of the SLE, respectively. Conversely, particulates of an intermediate size were characteristic of sampling locations situated between the mouth of the Saguenay Fjord and the mouth of the SLE. In the surface waters of SF and during spring, Chanut and Poulet (1982) found that SPM is commonly composed of very small particles (i.e., 2-3 $\mu \mathrm{m}$ ). Several investigations point out that suspended particulates in the SLE-SF regions are principally composed of inorganic matter (D'Anglejan and Smith, 1973; Larouche and Boyer-Villemaire, 2010; Mohammadpour et al., 2015). This mineral contribution may vary between 60 and $95 \%$ of dry weight depending on the geographic location and period of the year (Yeats, 1988; Larouche and BoyerVillemaire, 2010).

Despite their important contribution to the study of physical and chemical properties of SPM, none of these studies investigated relationships between chemical composition, size distribution, mass-normalized optical coefficients and optical proxies.

\subsection{Field surveys}

Discrete water samples for biogeochemical and optical measurements were obtained in 22 locations distributed throughout the SLE $(N=17)$ and $\operatorname{SF}(N=5)$ regions (Fig. 1$)$. One discrete sample was obtained in each sampling location except for site 6 , where two measurements were made during 3 and 6 June 2013. Surface samples (i.e., 0-2 m depth) were collected during 3-9 June 2013 by using an oceanographic rosette equipped with Niskin bottles (volume $=12 \mathrm{~L}$ ). For each study location, optically derived PSDs of unfractionated water samples and optical properties of different size fractions of SPM were determined onboard the ship.

\subsection{Biogeochemical analysis}

Size fractionation of SPM was done after sequentially filtering the original samples (i.e., volume $=12 \mathrm{~L}$ ) through pre-weighted membranes with a diameter of $47 \mathrm{~mm}$ and a pore size of $10 \mu \mathrm{m}$ (Whatman, polycarbonate), $0.7 \mu \mathrm{m}(\mathrm{GF} / \mathrm{F}$, Whatman, glass fiber), $0.4 \mu \mathrm{m}$ (Whatman, polycarbonate), and $0.2 \mu \mathrm{m}$ (Nuclepore, polycarbonate). The contribution of size fraction $i$ to the total mass of SPM $\left(F_{\mathrm{SPM}}{ }^{i}, i=0.2-0.4\right.$, $0.4-0.7,0.7-10$, and $>10 \mu \mathrm{m})$ was computed by normalizing the weight of the fraction $i$ by the sum of weights derived 


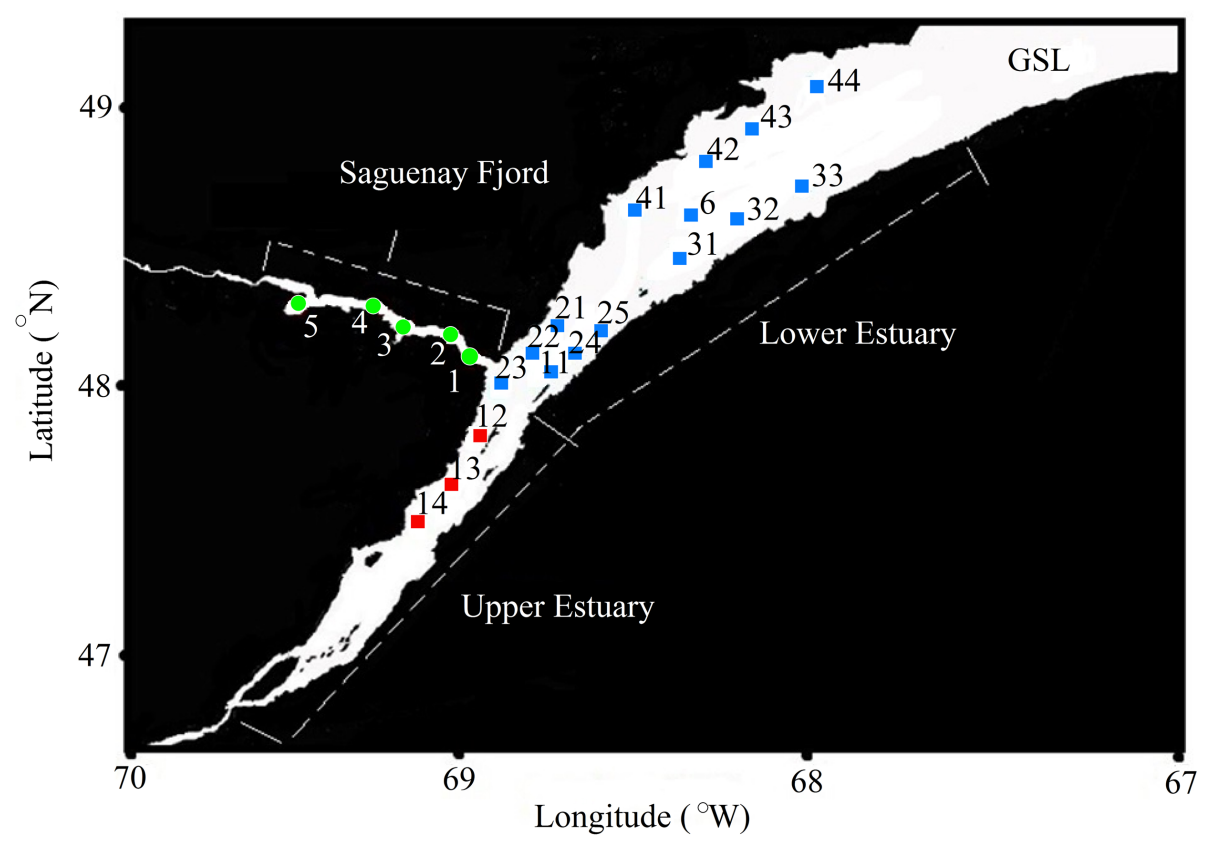

Figure 1. Study area. UE (red triangles), SF (green circles) and LE (blue rectangles) sub-regions. GSL is the Gulf of St. Lawrence.

from each size fraction. The contribution of PIM to total mass of SPM $\left(F_{\mathrm{SPM}}{ }^{\mathrm{PIM}}\right)$ was only computed for particulates with a grain size greater than $0.7 \mu \mathrm{m}$ (i.e., after filtering the original unfractionated sample trough a GF/F filter membrane). In this case, the mass of PIM and particulate organic matter (POM) was assumed to be negligible for particulates with a diameter smaller than $0.7 \mu \mathrm{m}$. This approximation should be verified in the future since the authors are not aware of publications addressing the contribution of relatively small particulates (i.e., $<0.7 \mu \mathrm{m}$ ) to PIM and POM. The mass of different SPM fractions was calculated based on pre-weighted filters. At the end of each filtration, sample filters were rinsed with deionized water to remove sea salts. PIM was obtained after removing the organic mass by combustion of original samples at $450^{\circ} \mathrm{C}$ and during $6 \mathrm{~h}$ (Mohammadpour et al., 2015).

The mass of POM was calculated as the difference between the dry mass of SPM concentrated in GF/F filters minus the dry mass of PIM. The precision of SPM mass determinations based on GF/F filters was $15 \%$ (Mohammadpour et al., 2015). This precision was computed as the percentage of \pm 1 standard deviation with respect to the arithmetic average of weight corresponding to 10 replicas. Based on loss-on-ignition factors (Barillé-Boyer et al., 2003) and clay composition data obtained in the Saint Lawrence Estuary (D'Anglejan and Smith, 1973), the estimated error of PIM determinations due to dehydration of clays was $3.1 \%$. Thus, PIM mass determinations have a maximum uncertainty of $18.1 \%$ due to the additional error of SPM mass measurements. Note that error in POM mass estimates was slightly greater than that associated with PIM mass estimates $(18.2 \%)$.

\subsection{Optical measurements}

The absorption and beam attenuation of unfractionated and size-fractionated water samples were measured using an absorption-beam attenuation meter (ac-s, WetLabs, $\lambda=400.3-747.5 \mathrm{~nm}$, average spectral resolution $=4 \mathrm{~nm}$, path length $=10 \mathrm{~cm}$, precision $\pm 0.001 \mathrm{~m}^{-1}$ ). In order to minimize the presence of bubbles, a pump (ISMATEC MCP$\mathrm{Z}$ ) was used to gently circulate the samples during the measurements. Spikes on the raw signal associated with bubbles were removed by visual inspection. The effect of scattering on the absorption measurements was minimized by applying a flat baseline at a reference wavelength of $715 \mathrm{~nm}$ (Bricaud and Stramski, 1990). This approximation implies no absorption at $715 \mathrm{~nm}$ and may result in anomalously low absorption values within the red and near-infrared (NIR) spectral range when optical measurements are done in relatively turbid waters (i.e., absorption coefficient $>0.2 \mathrm{~m}^{-1}$ ) (McKee et al., 2013). Also, these deviations are present when the proportional correction method (i.e., scattering correction directly related to magnitude of spectral attenuation coefficient) is applied (Zaneveld et al., 1994). Lastly, in situ calibrations were performed by using deionized water (Barnstead NANOpure water purification unit) as a reference (Twardowski et al., 1999). Pure water contribution was subtracted from absorption and beam attenuation measurements and resulting values were corrected for water temperature and salinity variations (Sullivan et al., 2006). Spectral values of $a_{\mathrm{SPM}}$ in $\mathrm{m}^{-1}$ were derived from unfractionated samples by subtracting the contribution of CDOM to the absorption measurements. The absorption due to CDOM was determined after pre-filtration of 
size-fractionated samples through a membrane with a pore size of $0.2 \mu \mathrm{m}$ (Nuclepore, Whatman). Similar to $a_{\text {SPM }}$ calculations, $c_{\text {SPM }}$ values were computed based on unfractionated samples after subtracting CDOM contributions to beam attenuation measurements. Lastly, particulate scattering coefficients $\left(b_{\mathrm{SPM}}\right)$ in $\mathrm{m}^{-1}$ were derived by subtracting $a_{\mathrm{SPM}}$ from $c_{\text {SPM }}$ values.

Bench determinations of PSD were made by using a redlaser (wavelength $=670 \mathrm{~nm}$ ) diffractometer (LISST-100X, type B, Sequoia Scientific) (Agrawal et al., 1991). Lab measurements were performed by using a chamber and a magnetic stir bar in order to homogenize the samples and avoid sinking of particulates. The optical path was covered with a black cloth to minimize ambient light contamination during the scattering measurements. The PSD derived with the LISST-100X has 32 size ranges logarithmically placed from 1.25 to $250 \mu \mathrm{m}$ in diameter (the upper size in each bin is 1.18 times the lower), with the width of individual size classes varying from 0.2 to $35 \mu \mathrm{m}$. Scattered light in the near-forward angles is measured on concentric detector rings and inversion modeling based on Mie theory yields the particle volume concentration, $V(D)$, in the 32 size classes (Agrawal and Pottsmith, 2000). Despite this, only the interval 3-170 $\mu \mathrm{m}$ was analyzed due to stray-light effects and variability of particle shape and refractive index in the first bins (i.e., $<3.2 \mu \mathrm{m}$ ) (Agrawal et al., 2008; Andrews et al., 2010; Reynolds et al., 2010) and bias related to particle sinking in the last bins (i.e.,

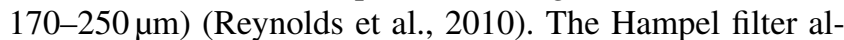
gorithm was applied to the original measurements in order to eliminate outliers (Pearson, 2005). Lastly, each final PSD estimate was computed as the average of measurements made during 3 min at a $1 \mathrm{~Hz}$ sampling rate.

The number of particles per unit of volume within each size class $(N(D))$ was computed by dividing $V(D)$ by the diameter $(D)$ of a volume-equivalent sphere corresponding to the midpoint of each individual class:

$N(D)=6 V(D)\left(\pi D^{3}\right)^{-1}$.

Estimates of $N(D)$ corresponding to 25 different size bins were calculated from inverting the measured volume scattering functions using an inversion based on Mie theory. The differential particle size distribution $\left(N^{\prime}(D)\right)$ was defined as the average number of particles within a given size class of width $\Delta D$ and per unit of volume (Reynolds et al., 2010):

$N^{\prime}(D)=N(D) \Delta D^{-1}$.

The power-law fit to the differential PSD was computed as follows:

$N^{\prime}(D)=N^{\prime}(D o)(D / D o)^{-\xi}$,

where $\xi$ is the slope of the PSD; Do is the reference particle diameter and was set to the midpoint of the size logarithmic size range (i.e., geometric mean $=35.17 \mu \mathrm{m}$ ). Calculations of $\xi$ were done by least squares minimization of log-transformed data (Reynolds et al., 2010). This method implicitly assumes that the relative error in particle counts is constant (e.g., a fixed percent). However, a more realistic error model should use a similar uncertainty for the area size distribution in each bin. The uncertainty of $\xi$ calculations, as estimated from 2 standard errors, varied between 1.6 and $10.2 \%$ with smaller errors in samples obtained in LE locations. Although PSD in natural waters may not follow the model proposed in Eq. (3), its use here was justified as our main interest was to have a first-order assessment of size effects of particulates on optical coefficient's variability. Also, the definition of $\xi$ based on LISST measurements applies for particulates greater than $2 \mu \mathrm{m}$. A more realistic representation of PSD is the model proposed by Risovic (1993). This parameterization mainly includes two particle populations ("large" and "small") with a different refractive index and has been recently applied in littoral environments by different studies (Zhang et al., 2013, 2014, 2017). Thus, relationships between $\xi$ and optical coefficients in this study are local and should not be generalized to other littoral environments.

\subsection{Optical proxies and characteristics of particle assemblages}

Another size proxy of suspended particulates is the power law exponential fit to the particulate beam attenuation spec$\operatorname{tra}(\gamma)$ (Boss et al., 2001). For a power-law PSD, $\gamma$ is related to the power-law exponent fit to the particle number size distribution $(\xi)\left(\xi=\gamma+3-0.5 e^{-6 \gamma}\right.$, Boss et al., 2001) and negatively related to the mean particle size.

The parameter $\gamma$ was derived as follows:

$c_{\mathrm{SPM}}(\lambda)=c_{\mathrm{SPM}}(\lambda r)(\lambda / \lambda r)^{-\gamma}$,

where $\lambda \mathrm{r}$ is the reference wavelength (Boss et al., 2001, 2013).

The uncertainty of $\gamma$ determinations varied between 2.2 and $6.4 \%$ with largest errors being computed in samples obtained in LE waters. The spectral slope of mass-specific particulate absorption coefficients (Svis) was calculated by nonlinear fitting of a single-exponential decay function over the visible range $400-700 \mathrm{~nm}$ :

$a_{x}^{*}(\lambda)=A e^{-\operatorname{Svis}(\lambda-400)}+B$,

where $x$ corresponds to the size class $i$ and the term $B$ corresponds to an offset at NIR wavelengths to account for nonzero absorption by mineral particles (Babin et al., 2003; Röttgers et al., 2014). In our case, $B$ is not different from zero due the initial correction of $a$ by scattering effects (see Sect. 2.4). Svis is a proxy for dithionite-extractable iron and organic carbon content of particulates of marine samples (Estapa et al., 2012). The uncertainty of Svis estimates varied between 0.5 and $21.5 \%$ with largest errors associated with samples obtained in LE locations. The Eq. (5) is only valid 
in waters where NAP is the main optical component contributing to light absorption coefficient of SPM.

\subsection{Mass-specific optical coefficients}

The spectral mass-specific absorption $\left(a_{i}^{*}(\lambda)\right)$ and scattering $\left(b_{i}{ }^{*}(\lambda)\right)$ coefficients in $\mathrm{m}^{2} \mathrm{~g}^{-1}$ and for different size fractions of SPM are defined as follows:

$a_{i}^{*}(\lambda)=a_{i}(\lambda)\left(w p_{i}\right)^{-1}$,

$b_{i}^{*}(\lambda)=b_{i}(\lambda)\left(w p_{i}\right)^{-1}$.

For each size class $i, a_{i}$ and $b_{i}$ are the coefficients of particulate absorption and scattering, respectively, and $w p_{i}$ is the mass of particulates per unit of volume in $\mathrm{g} \mathrm{m}^{-3}$ and for the size class $i$.

No measurements of $F_{\text {SPM }}{ }^{\text {PIM }}$ and $\xi$ were done in size fractions of SPM; thus it is difficult to compare PSD and particle chemical composition changes before and after the size fractionation of the samples. Size fractionation is anticipated to cause retention of smaller particulates in membranes of a larger pore size. These primary particles will overestimate the weight of the filtered sample and underestimate the weight of the next filtration step consisting in a membrane having a smaller pore size. Since particle sieving begins with large-sized particles and finishes with small-sized particles, the magnitude of $a_{i}{ }^{*}$ and $b_{i}{ }^{*}$ for relatively large (small) particulates is likely to be underestimated (overestimated). Bias on mass of particulates for each size fraction was verified by comparing the sum of weights of $0.7-10$ and $>10 \mu \mathrm{m}$ fractions with the weight of an independent sample after filtering it through a GF/F membrane (i.e., $0.7 \mu \mathrm{m}$ nominal pore size). In this case, the arithmetic average (median) of the relative bias for the whole dataset was 29.7 (24.9\%) or a 29.7 $(24.9 \%)$ overestimation with respect to samples without a previous size fractionation.

\subsection{Statistical analysis}

Relationships between PSD, particle chemical composition, optical proxies ( $\gamma$ and Svis) and mass-specific optical coefficients for different size fractions (i.e., $a_{i}{ }^{*}$ and $b_{i}{ }^{*}$ ) of SPM were investigated based on correlations with respect to $\xi$ and $F_{\text {SPM }}{ }^{\text {PIM }}$ variables. In all cases, the intensity and sign of correlations were quantified based on the non-parametric Spearman rank coefficient $\left(\rho_{\mathrm{S}}\right)$ (Spearman, 1904). Note that correlations of $\xi$ and $F_{\text {SPM }}{ }^{\text {PIM }}$ with mass-specific optical coefficients of size fractions $0.2-0.4$ and $0.4-0.7 \mu \mathrm{m}$ may only reflect dependencies between mass-normalized optical coefficients of different size classes since size spectra of $\xi$ and $F_{\text {SPM }}{ }^{\text {PIM }}$ calculations correspond to particles with a diameter greater than 2 and $0.7 \mu \mathrm{m}$, respectively.

\section{Results}

\subsection{Spatial variability of physical and chemical characteristics of SPM}

The size distribution of particulates varied among different sub-regions of the study area. In general, particulates with a diameter larger than $10 \mu \mathrm{m}$ had a relatively large contribution to the total SPM mass in UE locations $\left(F_{\mathrm{SPM}}>10 \mu \mathrm{m}\right.$ as percentage up to $17 \%$ ). This proportion was lower in the LE (up to $11 \%$ ) and SF (up to $15 \%$ ) sub-regions. The largest mass contribution of smallest-sized particulates (i.e., diameter $<0.4 \mu \mathrm{m}$ ) was calculated in the lower estuary (up to $27 \%$ ). Lastly, the intermediate size classes $0.4-$ 0.7 and $0.7-10 \mu \mathrm{m}$ were on average the fractions with the largest mass contributions to SPM in SF locations (up to 14 and $87 \%$, respectively). The arithmetic average of $\xi$ was not significantly different between the LE $(3.28 \pm 0.10$ (1 standard error), $N=15)$, UE $(3.46 \pm 0.21, N=3)$, and SF (3.42 $\pm 0.17, N=5)$ sub-regions. Unlike PSD, the mineral content of SPM was less variable between individual samples $\left(F_{\mathrm{SPM}}{ }^{\mathrm{PIM}}\right.$ range $=20$ to $\left.87 \%\right)$. On average, particle chemical composition in the UE, SF and LE sub-regions was dominated by minerals $\left(F_{\mathrm{SPM}}{ }^{\mathrm{PIM}}=0.57 \pm 0.34,0.53 \pm 0.07\right.$ and $0.50 \pm 0.09$ for UE, SF and LE, respectively).

\subsection{Mass-specific optical coefficients of particulates}

In general for the entire visible spectrum, the sub-regional average of mass-specific absorption particulate coefficients was higher in SF (e.g., $a_{\mathrm{SPM}^{*}}(440)=0.100 \pm 0.033 \mathrm{~m}^{2} \mathrm{~g}^{-1}$, arithmetic average \pm 2 standard errors) with respect to $\mathrm{UE}$ $\left(0.030 \pm 0.020 \mathrm{~m}^{2} \mathrm{~g}^{-1}\right)$ and LE $\left(0.011 \pm 0.004 \mathrm{~m}^{2} \mathrm{~g}^{-1}\right)$ locations (Fig. 2a). These differences were less pronounced within the red spectral range. In contrast, the sub-regional average of mass-specific particulate scattering coefficients was comparable between different spatial domains of the SLE (Fig. 2b). However, the highest and lowest values of the sub-regional averages of $b_{\mathrm{SPM}}{ }^{*}$ tended to be associated with $\mathrm{SF}$ (e.g., $\left.b_{\mathrm{SPM}}{ }^{*}(440)=0.356 \pm 0.092 \mathrm{~m}^{2} \mathrm{~g}^{-1}\right)$ and LE $\left(0.117 \pm 0.033 \mathrm{~m}^{2} \mathrm{~g}^{-1}\right)$ locations, respectively. In general for all size fractions of SPM, mass-specific absorption coefficients were usually higher in SF (e.g., $a_{i}{ }^{*}$ (440) up to $0.281 \mathrm{~m}^{2} \mathrm{~g}^{-1}$ for size range $\left.>10 \mu \mathrm{m}\right)$ with respect to UE and LE sub-regions (up to $0.211 \mathrm{~m}^{2} \mathrm{~g}^{-1}$ ) (Fig. 3). However, this pattern was reversed when the grain size of particulates was smaller than $0.4 \mu \mathrm{m}$ (Fig. 3a). Indeed, the highest $a_{0.2-0.4 \mu \mathrm{m}}{ }^{*}$ estimates in this study corresponded to UE waters (Fig. 3a).

In general, very high $a_{i}{ }^{*}$ values (e.g., up to $0.4 \mathrm{~m}^{2} \mathrm{~g}^{-1}$ at $\lambda=400 \mathrm{~nm}$ ) were associated with the size fraction of SPM with particulates with a diameter greater than $10 \mu \mathrm{m}$ (Fig. 3d). These values were up to 8 and 5 times higher than those characteristic of size fractions $0.4-0.7$ and $0.7-10 \mu \mathrm{m}$, respectively (Fig. $3 b-c)$. In general, $\xi$ and $F_{\text {SPM }}{ }^{\text {IM }}$ correlations with mass-specific absorption coefficients of different 


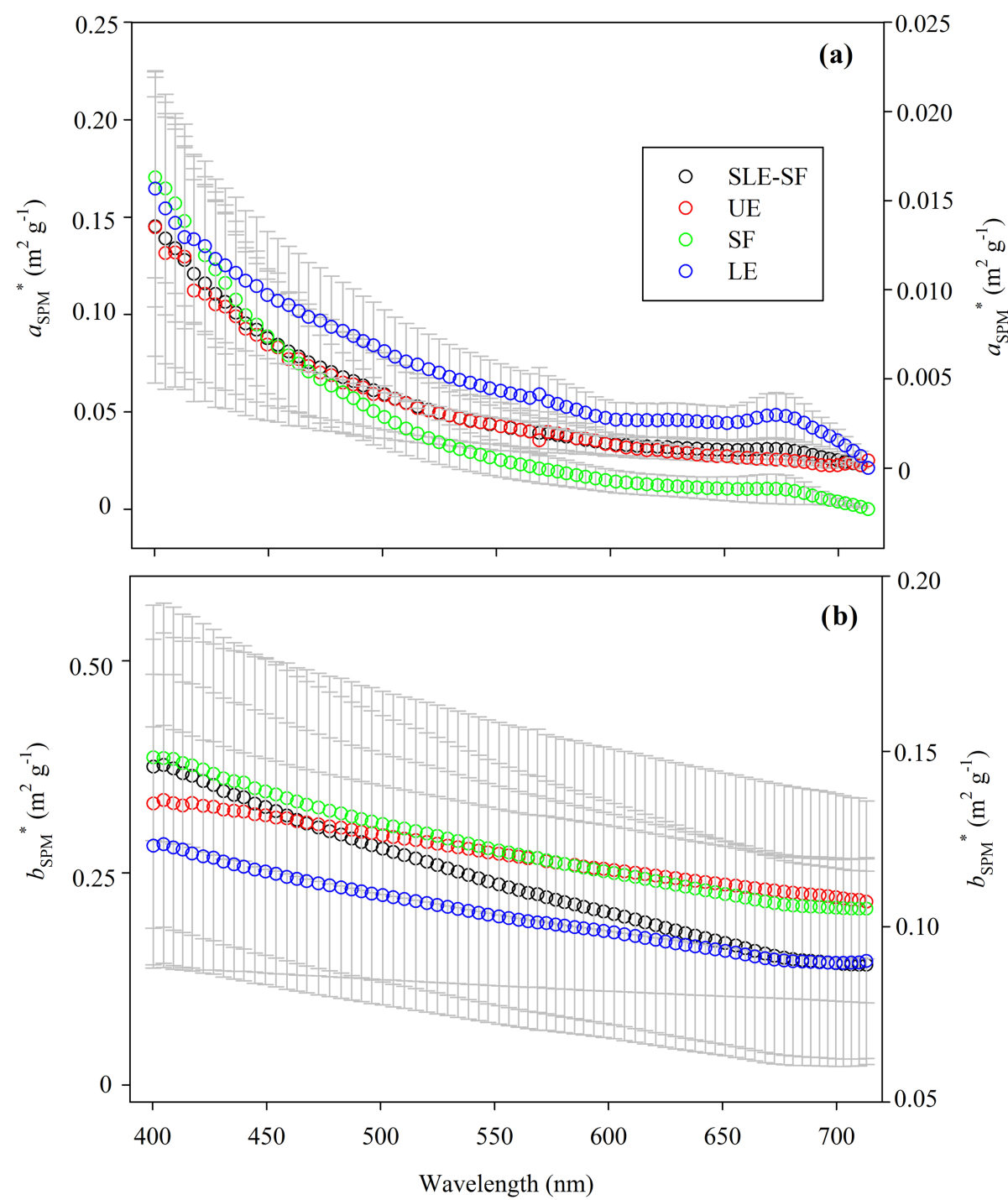

Figure 2. Spectral variation of mass-specific optical coefficients for total SPM. (a) $a_{\text {SPM }}$ (left axis SF; right axis UE, LE and SLE-SF) and (b) $b_{\text {SPM }}{ }^{*}$ (left axis SF and SLE-SF; right axis LE and UE). Each bar is the arithmetic average \pm 2 standard errors, as computed for SLE-SF (black circles), UE (red circles), SF (green circles) and LE (blue circles) sub-regions. The numbers of observations for UE, SF and LE sub-regions are 3, 5 and 15 respectively.

size fractions of SPM suggest that particle composition has a larger influence on $a_{i}^{*}(440)\left(\rho_{\mathrm{s}}\right.$ up to $\left.0.50, P=0.0009\right)$ with respect to $\mathrm{PSD}\left(\rho_{\mathrm{s}}\right.$ up to $\left.0.32, P=0.0033\right)$ (Table 2$)$.

The highest $b_{i}{ }^{*}$ values (up to $2.93 \mathrm{~m}^{2} \mathrm{~g}^{-1}$ at $\lambda=400 \mathrm{~nm}$ ) were associated with particulates within the size range 0.2 $0.4 \mu \mathrm{m}$ (Fig. 4). Note that mass-specific optical coefficients in the NIR spectral range are not shown due to the presence of negative values at some wavelengths. For the same size range of particulates, the highest $b_{i}{ }^{*}$ values were not always measured in the same region. Indeed, maximum $b_{i}{ }^{*}$ values for the size fractions $0.7-10 \mu \mathrm{m}$ (up to $0.96 \mathrm{~m}^{2} \mathrm{~g}^{-1}$ at $\lambda=556 \mathrm{~nm}$ ) and $>10 \mu \mathrm{m}$ (up to $0.46 \mathrm{~m}^{2} \mathrm{~g}^{-1}$ ) were obtained in UE and LE domains, respectively. Unlike $a_{i}{ }^{*}(440)$, $b_{i}{ }^{*}(550)$ variability was less influenced by changes in parti- cle composition ( $\rho_{\mathrm{s}}$ up to $0.42, P=0.0015$ ) (Table 2). Conversely, the impact of changing particle dimensions, as inferred from $\rho_{\mathrm{s}}$ correlations, had a larger effect on $b_{i}{ }^{*}(550)$ ( $\rho_{\mathrm{s}}$ up to $\left.0.37, P=0.006\right)$ with respect to $a_{i}^{*}(440)$ ( $\rho_{\mathrm{S}}$ up to $0.32, P=0.009)$ values

\subsection{Optical proxies}

Correlations between size and chemical fractions of SPM as derived from mass ratios and optical proxies are presented in Table 3. Over the whole study area, there was not a clear relationship between $\gamma$ and $F_{\mathrm{SPM}}{ }^{\text {PIM }}$ values $\left(\rho_{\mathrm{S}}=-0.34\right.$, $P=0.11)$. However, $\gamma$ changes were associated with variations of size-fractionated mass contributions of particu- 

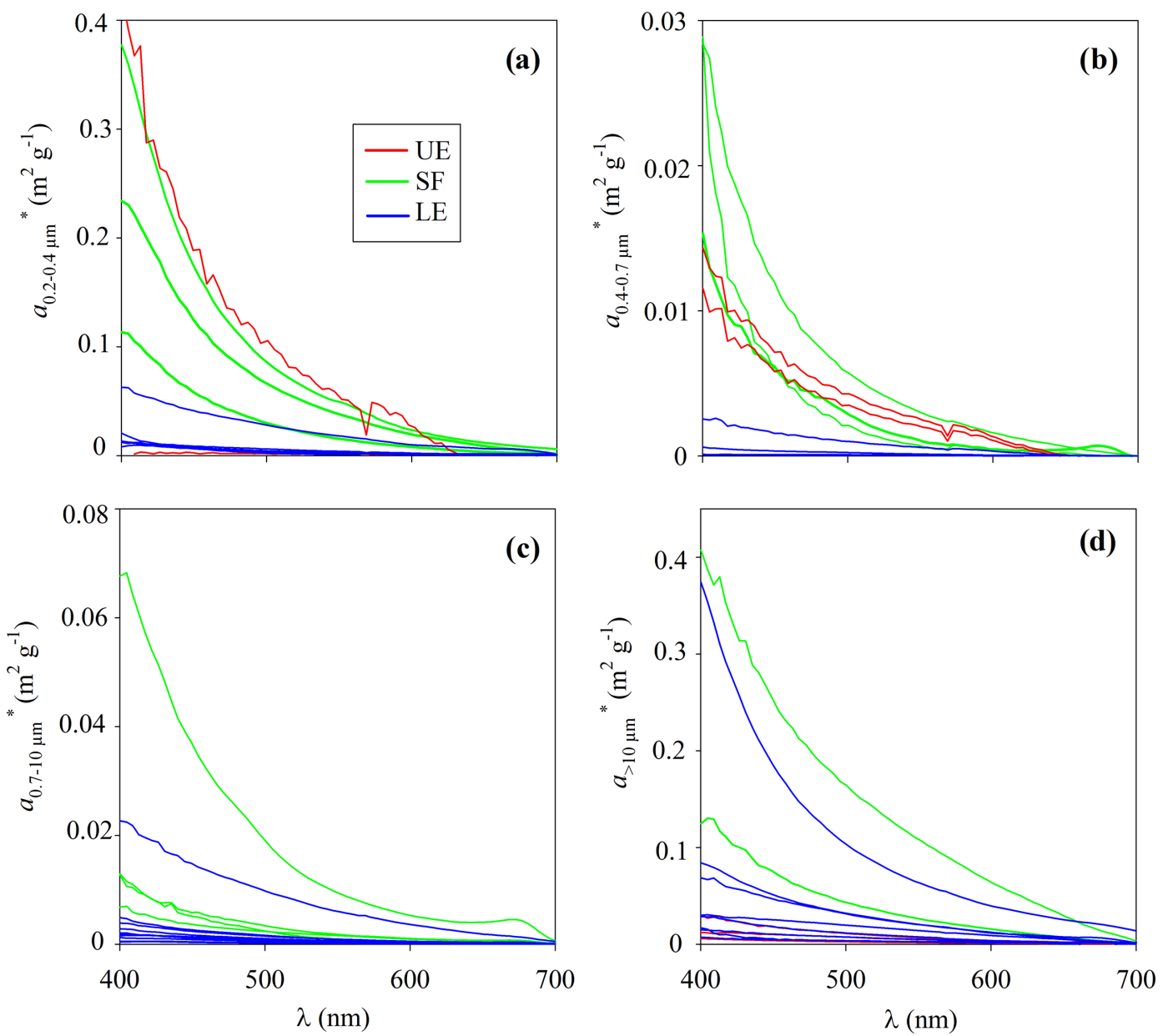

Figure 3. Spectral variation of mass-specific absorption coefficients for different size classes of suspended particulates: (a) $0.2-0.4 \mu \mathrm{m}$, (b) $0.4-0.7 \mu \mathrm{m}$, (c) $0.7-10 \mu \mathrm{m}$ and (d) $>10 \mu \mathrm{m}$. The color coding of symbols is similar to the one used in Fig. 2. Curves presenting negative values at some wavelengths are not depicted.

Table 2. Particle size and chemical composition effects on massspecific optical coefficients. Spearman rank correlations for $a_{i}{ }^{*}$ and $b_{i}{ }^{*}$ are computed at a wavelength of 440 and $550 \mathrm{~nm}$, respectively.

\begin{tabular}{llr}
\hline $\begin{array}{l}\text { Mass-specific } \\
\text { optical fraction }\end{array}$ & $\xi$ & $F_{\mathrm{SPM}}{ }^{\mathrm{PIM}}$ \\
\hline$a_{0.2-0.4 \mu \mathrm{m}}{ }^{*}$ & $0.32^{*}$ & $0.31^{*}$ \\
$a_{0.4-0.7 \mu \mathrm{m}^{*}}$ & $0.28^{*}$ & $0.50^{* *}$ \\
$a_{0.7-10 \mu \mathrm{m}^{*}}$ & $0.26^{*}$ & $0.49^{*}$ \\
$a_{>10 \mu \mathrm{m}}{ }^{*}$ & $0.31^{*}$ & $0.44^{*}$ \\
$b_{0.2-0.4 \mu \mathrm{m}}{ }^{*}$ & 0.15 & $-0.17^{*}$ \\
$b_{0.4-0.7 \mu \mathrm{m}}{ }^{*}$ & 0.05 & -0.06 \\
$b_{0.7-10 \mu \mathrm{m}^{*}}$ & $0.23^{*}$ & $0.42^{*}$ \\
$b_{>10 \mu \mathrm{m}}{ }^{*}$ & $0.37^{*}$ & $0.26^{*}$ \\
\hline
\end{tabular}

* and ** are the statistical significance $P$ at the 95 and $99 \%$ confidence level.

lates within the range $0.2-10 \mu \mathrm{m}\left(\rho_{\mathrm{s}}\right.$ up to $\left.0.53, P=0.01\right)$. The sign of this correlation varied depending on the size class under investigation (e.g., positive and negative $\rho_{\mathrm{s}}$ values for small-sized and intermediate-sized particulates, respectively). There was no clear relationship between $\gamma$ and $\xi$ values for samples obtained over the whole study area $\left(\rho_{\mathrm{s}}=0.15, P=0.49, N=23\right)$. The range of $\gamma$ values was $0.759-3.282,1.389-1.534,2.873-3.282$ and $0.759-1.802$ for the SLE, UE, SF and UE domains, respectively. The spectra slope of $a_{\mathrm{SPM}}{ }^{*}$ was not statistically related to $F_{\mathrm{SPM}}{ }^{\mathrm{PIM}}$ changes $\left(\rho_{\mathrm{s}}=-0.06, P=0.78, N=23\right)$. However, Svis variability was strongly connected with changes in mass contribution of different size classes of SPM and, in particular, those associated with small-sized particulates (i.e., 0.2$0.7 \mu \mathrm{m}$ ) (Table 3). This pattern was consistent with a positive correlation between $\gamma$ and Svis $\left(\rho_{\mathrm{s}}=-0.489, P=0.018\right.$, $N=23$ ). However, there was no clear relationship between Svis and $\xi$ values $\left(\rho_{\mathrm{s}}=0.123, P=0.57, N=23\right)$.

The range of Svis values for unfractionated samples of SLE-SF, UE, SF and UE domains was 0.005-0.051, $0.009-0.017,0.014-0.051$ and $0.005-0.016 \mathrm{~nm}^{-1}$, respec- 

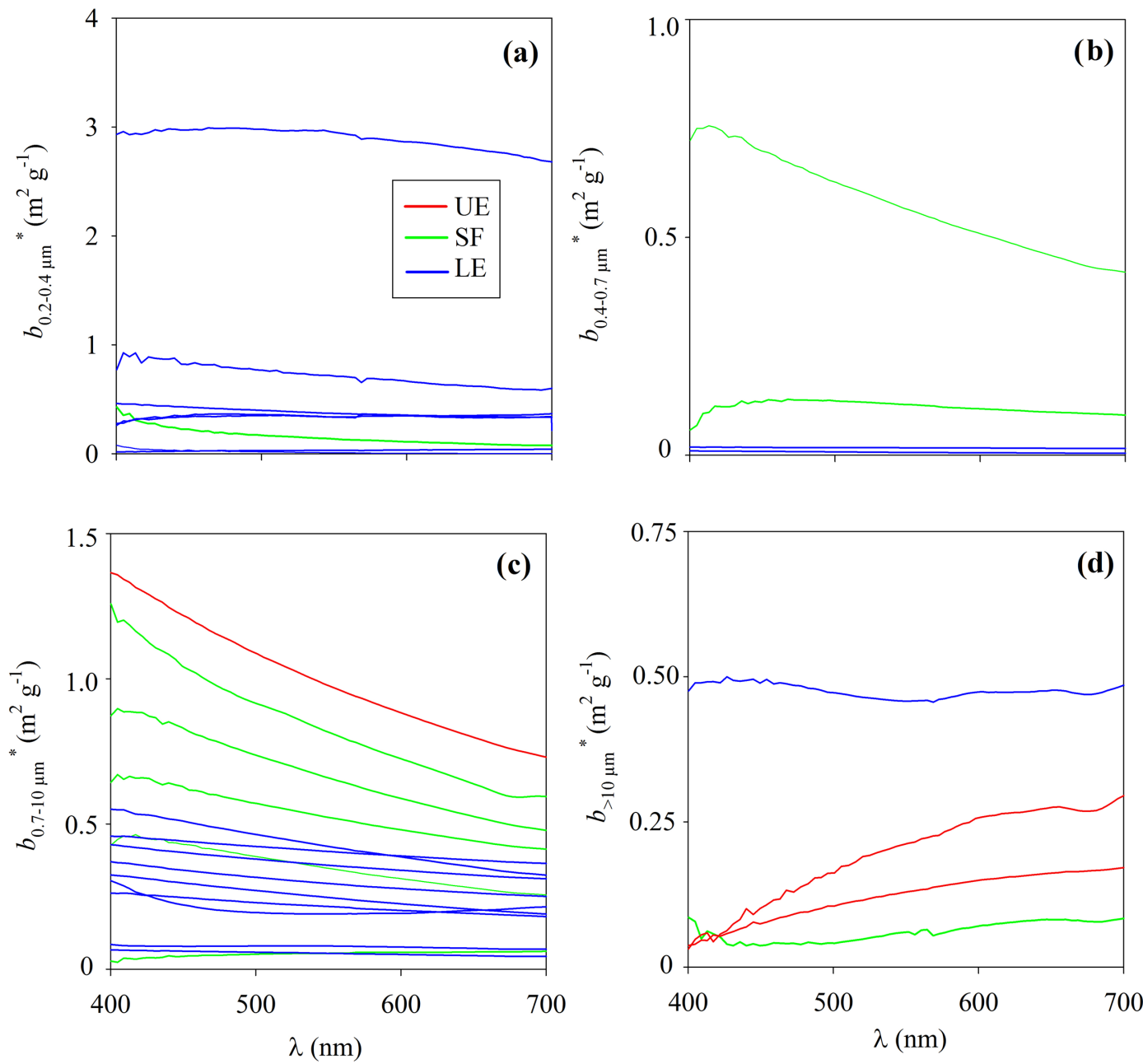

Figure 4. Spectral variation of mass-specific scattering coefficients for different size classes of suspended particulates. Size classes and color coding of symbols idem as Fig. 3. Curves presenting negative values at some wavelengths are not depicted.

Table 3. Correlation of optical proxies with mass-derived size and chemical fractions of SPM. Spearman rank correlations based on 23 samples.

\begin{tabular}{lrr}
\hline Mass fraction & $\gamma$ & Svis \\
\hline$F_{\mathrm{SPM}}{ }^{\mathrm{PIM}}$ & -0.34 & -0.06 \\
$F_{\mathrm{SPM}}{ }^{0.2-0.4 \mu \mathrm{m}}$ & $0.53^{*}$ & $0.49^{* *}$ \\
$F_{\mathrm{SPM}}{ }^{0.4-0.7 \mu \mathrm{m}}$ & $-0.43^{*}$ & $-0.49 * *$ \\
$F_{\mathrm{SPM}}{ }^{>010 \mu \mathrm{m}}$ & $-0.38^{*}$ & $-0.30 *$ \\
$F_{\mathrm{SPM}}$ & 0.13 & 0.19 \\
\hline
\end{tabular}

tively. Over the whole study area, the range of Svis values for SPM size fractions 0.2-0.4, 0.4-0.7, 0.7-10 and $>10 \mu \mathrm{m}$ was $0.004-0.026,0.007-0.052,0.004-0.109$ and $0.001-0.028 \mathrm{~nm}^{-1}$, respectively. In general, Svis slopes of different size fractions were not correlated even though the variation of Svis for unfractionated samples was strongly linked to changes in Svis estimates associated with particulates within the size range $0.7-10 \mu \mathrm{m}\left(\rho_{\mathrm{s}}=0.66, P=0.004\right)$.

\section{Discussion}

\subsection{Uncertainty of optical measurements}

Inherent optical properties in this study were derived from an ac-s instrument. Thus, large errors on absorption coefficients may be anticipated in relatively turbid waters if original measurements are not corrected for scattering effects (Boss et al., 2009; McKee et al., 2013). These effects are mainly attributed to the acceptance angle of the transmissometer and the multiple scattering of photons. The acceptance angle of the ac-s instrument is $\sim 0.9^{\circ}$ and much larger than that corresponding to the LISST-100X diffractometer $\left(\sim 0.027^{\circ}\right)$; thus, a larger underestimation of the theoretical particulate beam attenuation is expected in the ac-s with respect to LISST100X measurements due to a larger contribution of forward- 
scattered photons arriving at the detector of the ac-s (Boss et al., 2009). Unfortunately, $c$ deviations due to acceptance angle variations were not corrected in this study due to the lack of $c$ values as obtained by using an integrating cavity absorption meter (e.g., PSICAM) (Röttgers et al., 2005). Note that these differences are much greater with respect to the standard deviation of each sample determination in this study and computed based on ac-s measurements (e.g., $<1 \%$ at $\lambda=532 \mathrm{~nm}, n=100$ ).

In this investigation, the "flat" baseline correction was selected for correcting the scattering effects on absorption coefficient estimates as derived from ac-s measurements. This technique was chosen due to the lack of PSICAM measurements or ancillary optical information (e.g., particle backscattering efficiency) to tune up a Monte Carlo scattering correction approach (McKee et al., 2008). Since NAP is an important component of SLE-SF environments, an underestimation of ac-s absorption measurements is expected due to a nonzero absorption at $715 \mathrm{~nm}$ (McKee et al., 2013; Röttgers et al., 2013). This deviation is amplified at wavelengths greater than $600 \mathrm{~nm}$, is more remarkable at higher turbidities and decreases when phytoplankton contribution to total particulate absorption increases. To minimize this residual scattering, an empirical correction linking PSICAM and ac-9 absorption measurements at $715 \mathrm{~nm}$ has been proposed (Röttgers et al., 2013). Although practical, it is uncertain whether the use of this correction in our study area is valid due to optical differences between particle assemblages of the SLS-SF and those studied by Röttgers et al. (2013). Thus, the magnitude of optical coefficients of particulates measured in SLE-SF waters may present large errors (i.e., $>50 \%$ ) with respect to PSICAM measurements and at wavelengths longer than $550 \mathrm{~nm}$. Indeed, Röttgers et al. (2013) reported a relative error up to $70 \%$ on absorption measurements corrected using the flat scattering correction and made at a wavelength of $630 \mathrm{~nm}$. This bias is anticipated to be maximum (minimum) in UE (LE) locations due to the greater contribution of NAP to particulate absorption of the former sub-region. In addition to the bias caused by scattering effects and spectrophotometric calibrations of absorption values (up to $2 \%$ ) (Röttgers et al., 2013) by ac-s and PSICAM instruments, respectively, the error on mass-specific optical coefficients computed from ac-s and PSICAM measurements will also include an error of $15 \%$ due to the uncertainty of SPM weight determinations.

\subsection{Variability of physical and chemical characteristics of SPM}

A striking finding in this study was the important weight contribution of relatively large particulates (i.e., $>10 \mu \mathrm{m}$ ) to the total mass of SPM in UE waters. This phenomenon was likely attributed to the active resuspension of sediments associated with vertical mixing produced by tidal currents and winds (Yeats, 1988). Conversely, this effect was secondary in relatively deep waters of SF and LE where large and heavy particulates are rapidly removed from the water column and deposited along submarine canyons (Gagné et al., 2009). The chemical composition of size-fractionated SPM was not analyzed in this study. However, the correlation between $F_{\mathrm{SPM}}{ }^{\mathrm{PIM}}$ and $F_{\mathrm{SPM}}{ }^{0.2-0.7 \mu \mathrm{m}}$ values suggest that mineral content of SPM increases as the contribution of particulates with a diameter smaller than $0.7 \mu \mathrm{m}$ becomes larger $\left(\rho_{\mathrm{s}}=0.30\right.$, $P=0.035, N=23$ ). This finding is consistent with previous studies in the SLE showing that relatively small (i.e., diameter $\sim 2 \mu \mathrm{m}$ ) particulates are mainly composed by inorganic matter (Yeats, 1988; Gagné et al., 2009). A large proportion of particulates with a diameter above $50 \mu \mathrm{m}$ and lower $\xi$ values were typically found in LE locations. These results go along with historical datasets and showing a greater proportion of relatively large particulates (i.e., $>5$ and $<50 \mu \mathrm{m}$ ) over the LE locations and during the same period of the year (Chanut and Poulet, 1982).

\subsection{Spatial variability of mass-normalized optical coefficients}

$a_{\mathrm{SPM}}{ }^{*}$ measurements in the visible and NIR range had a large variability that was comparable to the range of values reported in the literature for temperate coastal waters (e.g., Mobile Bay, Elbe Estuary, Gironde Estuary) (Snyder et al., 2008; Doxaran et al., 2009; Röttgers et al., 2014) (Table 4). Also, our values in the blue spectral range are within the interval of variation (e.g., $0.024-0.031 \mathrm{~m}^{2} \mathrm{~g}^{-1}, \lambda=440 \mathrm{~nm}$ ) of the linear regression slope between NAP absorption coefficient and SPM concentration values measured in mineralrich waters (i.e., $a_{\mathrm{SPM}^{*}} \cong a_{\mathrm{NAP}}{ }^{*}$ ) (Bowers et al., 1996; Babin et al., 2003). This is remarkable given the large diversity of methodologies used by different research teams for estimating $a_{\mathrm{SPM}}{ }^{*}$ values (e.g., pad technique, ac-s, integrating sphere). In general, the lowest $a_{\mathrm{SPM}}{ }^{*}$ values (i.e., $0.01-$ $0.02 \mathrm{~m}^{2} \mathrm{~g}^{-1}$ at $\lambda=440 \mathrm{~nm}$ ) commonly corresponded with samples obtained in very turbid environments (i.e., $>100$ $\mathrm{g} \mathrm{m}^{-3}$, Mississippi River and Delta, Gironde River) (Bowers and Binding, 2006; D'Sa et al., 2006; Doxaran et al., 2009). These low values could be overestimated due to an increase on particulate absorption associated with an incomplete removal of multiple scattering effects. Relatively low $a_{\mathrm{SPM}}{ }^{*}$ values have been linked to high POC / SPM (Wozniak et al., 2010) and Chl / SPM concentration ratios, where Chl means chlorophyll a concentration (Estapa et al., 2012). In this study, dimensionless $\mathrm{Chl} /$ SPM ratios varied between $3.9 \times 10^{-5}$ and $1.8 \times 10^{-3}$ with a median of $1.1 \times 10^{-4}$ and an arithmetic mean of $2.7 \times 10^{-4}$. These values are commonly lower than those reported in coastal waters of the Gulf of Mexico by D'Sa et al. (2006) $\left(\sim 10^{-3}\right)$, and is consistent with the relatively high $a_{\mathrm{SPM}}{ }^{*}$ values obtained in SLS-SF waters.

A well-known mechanism explaining the general decrease in $a_{\mathrm{SPM}^{*}}{ }^{*}$ in very turbid waters is related to the packag- 
Table 4. Mass-specific optical coefficients of suspended particulates for different littoral environments. Acronyms and units are defined in Table 1.

\begin{tabular}{|c|c|c|c|c|c|}
\hline Location & $\lambda$ & $a_{\mathrm{SPM}}{ }^{*}$ & $b_{\mathrm{SPM}}{ }^{*}$ & {$[\mathrm{SPM}]^{\mathrm{i}}$} & References \\
\hline \multirow[t]{5}{*}{ SLE-SF } & 440 & $0.001-0.073^{\mathrm{a}}$ & $0.015-0.511^{\mathrm{a}}$ & $2.28-30.6$ & This study \\
\hline & 488 & $0.001-0.040$ & $0.013-0.472$ & & \\
\hline & 556 & $0.001-0.017$ & $0.012-0.424$ & & \\
\hline & 665 & $0.001-0.004$ & $0.010-0.365$ & & \\
\hline & 708 & $0.001-0.002$ & $0.010-0.338$ & & \\
\hline Elbe River, & 650 & $0.001-0.020^{\mathrm{b}}$ & & $0.5-10$ & Röttgers et al. (2014) \\
\hline German Bight, & 750 & $0.001-0.019$ & & & \\
\hline Baltic Sea, & 850 & $0.001-0.014$ & & & \\
\hline \multicolumn{6}{|l|}{ New Caledonia lagoon } \\
\hline Monterey Bay, USA & 532 & & $0.46-2.54^{\mathrm{c}}$ & $0.11-2.37$ & Zhang et al. (2014) \\
\hline Mobile Bay, USA & 532 & & $0.40-1.78$ & $0.26-7.36$ & \\
\hline Mobile Bay, & 440 & & $0.44-1.95^{\mathrm{d}}$ & $0.23-25.32$ & Stavn and Richter (2008) \\
\hline \multirow[t]{4}{*}{ Southwest Pass, USA } & 488 & & $0.41-1.89$ & & \\
\hline & 550 & & $0.40-1.80$ & & \\
\hline & 676 & & $0.36-1.63$ & & \\
\hline & 715 & & $0.34-1.61$ & & \\
\hline Coast of New Jersey, & 440 & & & $0.44-6.6$ & Snyder et al. (2008) \\
\hline Monterey Bay, & 488 & & & & \\
\hline Great Bay & 556 & & & & \\
\hline Mobile Bay & 665 & $\begin{array}{r}0.05 \pm 0.01^{\mathrm{d}} \\
\text { (arithmetic mean } \pm \\
\text { standard deviation) }\end{array}$ & & & \\
\hline Irish Sea, UK & 665 & & $0.08-0.45^{\mathrm{e}}$ & $1.9-26.5$ & Binding et al. (2005) \\
\hline \multirow[t]{4}{*}{ Irish Sea, UK } & 443 & $0.062 \pm 0.013^{\mathrm{f}}$ & $0.17-0.19$ & $1.6-50$ & Bowers and Binding (2006) \\
\hline & 490 & & $0.20-0.22$ & & \\
\hline & 555 & & $0.20-0.24$ & & \\
\hline & 665 & & $0.14-0.15$ & & \\
\hline $\begin{array}{l}\text { Coastal waters of Europe } \\
\text { and French Guiana }\end{array}$ & 676 & & $0.63-2.07^{\mathrm{g}}$ & $1.2-82.4$ & Neukermans et al. (2012) \\
\hline \multirow[t]{2}{*}{ Elbe Estuary, Germany } & 555 & $0.05-0.07^{\mathrm{d}}$ & $0.35-0.47$ & $73.5-294.2$ & Doxaran et al. (2009) \\
\hline & 715 & $0.01-0.03$ & $0.32-0.44$ & & \\
\hline \multirow[t]{2}{*}{ Gironde Estuary, France } & 555 & $0.02-0.06$ & $0.28-0.50$ & $21.9-344.1$ & \\
\hline & 715 & $0.01-0.02$ & $0.27-0.45$ & & \\
\hline \multirow{4}{*}{$\begin{array}{l}\text { Coastal Louisiana } \\
\text { and lower Atchafalaya } \\
\text { and Mississippi rivers }\end{array}$} & 440 & $\begin{array}{r}0.056 \pm 0.012^{\mathrm{g}} \\
(0.05-0.065)\end{array}$ & & & Estapa et al. (2012) \\
\hline & 488 & $0.035-0.05$ & & & \\
\hline & 556 & $0.25-0.35$ & & & \\
\hline & 665 & $0.125-0.02$ & & & \\
\hline West of Mississippi Delta & 443 & $0.012-0.079^{\mathrm{d}}$ & & & D'Sa et al. (2006) \\
\hline \multirow[t]{5}{*}{ Imperial Beach, California } & 440 & $0.03-0.1^{\mathrm{h}}$ & $0.1-1.2$ & $3-90$ & Wozniak et al. (2010) \\
\hline & 488 & $0.02-0.08$ & $0.18-0.9$ & & \\
\hline & 556 & $0.01-0.03$ & $0.2-0.9$ & & \\
\hline & 665 & $0.004-0.02$ & $0.2-0.8$ & & \\
\hline & 708 & $0.001-0.02$ & $0.2-0.8$ & & \\
\hline
\end{tabular}

\footnotetext{
${ }^{\mathrm{a}}$ ac-s measurements and sum of weights of SPM size fractions $0.2-0.4,0.4-0.7,0.7-10$ and $>10 \mu \mathrm{m} .{ }^{\mathrm{b}}$ Integrating sphere coupled to spectrophotometer for suspensions and pad technique, SPM weight based on GF/F (pore size $=0.7 \mu \mathrm{m}$ ) and Nuclepore Whatman (pore size $=0.4 \mu \mathrm{m}$ ) filters. ${ }^{\mathrm{c}}$ Multispectral volume scattering meter and optical models for different particle subpopulations with asymmetrical shape. ${ }^{\mathrm{d}}$ ac- 9 measurements and SPM weight based on GF/F filters. ${ }^{\mathrm{e}}$ Irradiance meter PRR600 and optical models for estimating inherent optical properties and SPM weight based on GF/F filters. ${ }^{\mathrm{f}} \mathrm{Comparable} \mathrm{to}{ }^{\mathrm{e}}$ but pad technique for estimating absorption coefficients of SPM, ${ }^{g}$ comparable to ${ }^{\mathrm{d}}$ but using ac-s measurements. ${ }^{\mathrm{g}}$ Comparable to ${ }^{\mathrm{b}}$ but using only suspensions and weight based on GF/F filters. ${ }^{h}$ Comparable to ${ }^{b}$ but using only GF/F filters for SPM weight. ${ }^{i}$ Concentration of SPM in $\mathrm{g} \mathrm{m}^{-3}$ and for particulates retained in glass-fiber filters with a pore size of $0.7 \mu \mathrm{m}$.
} 
ing effects (Duysens, 1956; Morel, 1974). At higher turbidities, larger particulates contribute to PSD variations; thus, as mean diameter of particles increases, the light absorption efficiency per mass decreases (i.e., the interior of larger particles has a greater "shading"). This could also explain the spatial differences of $a_{\mathrm{SPM}}{ }^{*}(440)$ in our study area where larger values corresponded with surface waters dominated by particle assemblages with a smaller mean diameter (e.g., UE and SF). In nearshore waters of California, Wozniak et al. (2010) demonstrated inverse relationships between $a_{\mathrm{SPM}}{ }^{*}(440)$ and the median particle diameter of inorganicand organic-dominated assemblages.

Indirect size effects on $a_{\mathrm{SPM}}{ }^{*}$ (440) due to iron content per particle have been discussed by Estapa et al. (2012) in environments where optical properties are dominated by NAP. In general, smaller particulates have a greater surface for adsorbing organic compounds where iron can accumulate (Mayer, 1994; Poulton and Raiswell, 2005). Thus, SPM fractions with small-sized particulates are expected to have an enhancement of $a_{\mathrm{SPM}}{ }^{*}(440)$ due to relatively high iron concentrations. This phenomenon could probably explain part of the $a_{\mathrm{SPM}}{ }^{*}(440)$ variability in some locations of our study area where relatively high concentrations of iron bound to particulates have been measured (e.g., SF) (Yeats and Bewers, 1976; Tremblay and Gagné, 2009).

Similar to $a_{\mathrm{SPM}^{*}}{ }^{*}, b_{\mathrm{SPM}}{ }^{*}$ values were highly variable between locations but within the range reported in other littoral environments (e.g., Irish Sea, off the coast of Europe and French Guiana) (Bowers and Binding, 2006; Neukermans et al., 2012) (Table 4). In this study, the spectral variation $b_{\mathrm{SPM}}{ }^{*}$ between regions showed a spectral flattening as particle assemblages become dominated by organic matter (i.e., LE). This finding is consistent with Wozniak et al. (2010) determinations made at Imperial Beach, California.

\subsection{Relationships between PSD, particle chemical composition and mass-specific optical coefficients}

For all size fractions of SPM, $\xi$ was positively correlated with $a_{i}^{*}(440)$ ( $\rho_{\mathrm{s}}$ up to $\left.0.32, P=0.006\right)$. This pattern suggests a higher absorption efficiency of relatively small-sized particulates. Since particle aggregates were altered during our experiments, the influence of particle density on massspecific optical coefficients cannot be quantified as this effect is mainly observed in undisrupted marine aggregates (Slade et al., 2011; Neukermans et al., 2012, 2016). Change in PSD due to aggregation with substantial reduction of absorption (i.e., $50 \%$ ) due to the packaging effect is expected to be important at $d \sim 0.25 \lambda / n$, where $d$ is the diameter of the particle and $n$ ' is the imaginary part of the index of refraction (Stemmann and Boss, 2012). By assuming $n^{\prime}=0.0025$ for a mixed particle assemblage of clays (i.e., kaolinite + montmorillonite) and $\lambda=300 \mathrm{~nm}$, the resulting $d$ is $30 \mu \mathrm{m}$. Based on simulations, the formation of clayderived aggregates may cause a change in $a_{\mathrm{SPM}^{*}}{ }^{*}$ of approx- imately $10 \%$ (Estapa et al., 2012). This effect will be larger or smaller depending on aggregate size, solid mass fraction and primary particle size.

In general, $\xi$ was positively correlated with $b_{i}{ }^{*}(550)\left(\rho_{\mathrm{s}}\right.$ up to $0.37, P=0.008)$ and suggests an increase in scattering efficiency for smaller particulates. Values of $a_{i}{ }^{*}(440)$ and $b_{i}{ }^{*}(550)$ had a comparable correlation with $\xi$ even though the Spearman coefficients tended to be higher for $b_{i}{ }^{*}(550)$ determinations. Also, correlations between $b_{i}{ }^{*}(550)$ and $\xi$ was more remarkable when particulates were large-sized. In Arctic waters, Reynolds et al. (2016) observed an increase on mass-specific particulate backscattering for mineral-rich particle assemblages that tend to exhibit steeper PSDs. Although no particulate backscattering measurements were available in this study, Reynolds et al. (2016) highlight the importance of PSD for driving variations on mass-specific optical coefficients linked to scattering processes.

A common pattern in all size fractions of SPM was the stronger correlation of $F_{\mathrm{SPM}}{ }^{\mathrm{PIM}}$ with $a_{i}{ }^{*}(440)$ compared with $b_{i}{ }^{*}(550)$ values. The enrichment of suspended particulates in inorganic matter and the concomitant variations in $a_{i}{ }^{*}(440)$ may be attributed to mineral-associated iron (Babin and Strasmki, 2004; Estapa et al., 2012) and/or organicassociated iron (Estapa et al., 2012). More studies are needed to test this hypothesis; however, it is interesting to note that high $a_{\mathrm{SPM}}{ }^{*}$ values in our study were commonly associated with SF locations where reduced iron associated with particulates is typically high (Deflandre et al., 2002).

\subsection{Optical proxies of SPM characteristics}

The variability of $\gamma$ was related to mass contribution changes of specific size fractions of SPM ( $\rho_{\mathrm{s}}$ up to $0.53, P=0.004$, $i=0.2-0.4 \mu \mathrm{m})$. Conversely, $\gamma$ was not correlated with the mass contribution of minerals to SPM. Despite the major effects of particle size classes on $\gamma, \gamma$ was not clearly correlated with $\xi$. In oceanic waters, $\xi$ and $\gamma$ values covary in a linear way for a specific range of refractive index and $\xi$ (Boss et al., 2001; Twardowski et al., 2001). These covariations were observed for $\xi$ values derived from LISST and Coulter counter measurements (Boss et al., 2001; Slade and Boss, $2015)$. Our range of $\xi$ values was within the natural variability reported in coastal and oceanic environments $(\xi=2-$ 4.5) (Reynolds et al., 2010; Neukermans et al., 2012; Xi et al., 2014). Also, the magnitude of $\gamma$ in our samples (0.29$2.22 \mathrm{~nm}^{-1}$ ) was within the range of values that characterize oceanic environments (0.2-2) (Twardowski et al., 2001; Boss et al., 2013). Unlike oceanic waters, the poor correspondence between $\xi$ and $\gamma$ values in this study is linked to the finite acceptance angle of the ac meter (Slade and Boss, 2015).

The variability of Svis values in this study was relatively high ( 10-fold) with respect to other littoral environments $\left(1.3\right.$-fold, Svis $\left.=0.009-0.0113 \mathrm{~nm}^{-1}\right)$ (Estapa et al., 2012). Svis was inversely related to $a_{\mathrm{SPM}^{*}}{ }^{*}(440)$ in surface waters of the SLE with a major marine influence (i.e., salin- 
ity range $=29-33.5$, LE locations $)\left(\rho_{\mathrm{s}}=-0.55, P=0.04\right.$, $N=14$ ). This pattern was previously detected in coastal waters of the Gulf of Mexico (Estapa et al., 2012).

\section{Conclusions}

The measure of mass-specific optical coefficients of SPM is essential for developing optical inversions for mapping biogeo-chemical components in surface waters and improving our understanding regarding the origin of optical signatures in remote sensing studies. In this contribution, we presented, for the first time, mass-specific scattering and absorption coefficients of size-fractionated SPM in estuarine waters of the Saint Lawrence River and a major SLE tributary, the Saguenay Fjord.

Despite the intrinsic variability of weight-normalized optical coefficients due to variations of physical and chemical properties of particle assemblages, the following patterns were identified: (1) the mass-specific absorption coefficient of different size fractions of SPM was preferentially related to changes in particle chemical composition as inferred from changes in $F_{\mathrm{SPM}}{ }^{\mathrm{PIM}}$ and at a wavelength of $440 \mathrm{~nm}$, (2) the magnitude of $\xi$ was correlated with $b_{i}{ }^{*}(550)$ and $a_{i}{ }^{*}(440)$ in a comparable way, and (3) the magnitude of Svis was inversely correlated with $a_{\mathrm{SPM}}{ }^{*}(440)$ in areas with a larger marine influence (i.e., lower estuary). In summary, these relationships will be useful for investigating local and regionally limited biogeo-optical properties of SPM. Thus, additional research based on true optical properties of PSD will be needed in order to propose more general relationships that can be applied to other littoral environments.

Data availability. The in situ measurements are available upon request from the corresponding author (martinalejandro_montes@uqar.ca).

Competing interests. The authors declare that they have no conflict of interest.

Acknowledgements. This investigation was supported by the Natural Sciences and Engineering Research Council of Canada, Individual Discovery grant, project title "Optical remote Sensing models of suspended Particulate matter in the St. Lawrence Estuary" (OSPLE), awarded to Martin A. Montes-Hugo. We thank the crew of the Creed and Alexandre Palardy for their assistance during the field work. Also, we appreciate the support of ISMER technicians Pascal Rioux and Dominique Lavallée during the field surveys and the processing of lab measurements. Lastly, we are indebted to an anonymous reviewer and Robert H. Stavn for constructive comments and to Emmanuel Boss for suggestions which helped to greatly improve the original manuscript.

Edited by: Emmanuel Boss

Reviewed by: two anonymous referees

\section{References}

Agrawal, Y., McCave I., and Riley J.: Laser diffraction size analysis, in: Principles, Methods, and Application of Particle Size Analysis, edited by: J. P. M. Syvitski, Cambridge University Press, NY, USA, 119-129, https://doi.org/10.1017/CBO9780511626142, 1991.

Agrawal, Y. C. and Pottsmith, H. C.: Instruments for particle size and settling velocity observations in sediment transport, Mar. Geol., 168, 89-114, https://doi.org/10.1016/S00253227(00)00044-X, 2000.

Agrawal, Y. C., Whitmire, A., Mikkelsen, O. A. and Pottsmith, H. C.: Light scattering by random shaped particles and consequences of measuring suspended sediments by laser diffraction, J. Geophys. Res., 113, C04023, https://doi.org/10.1029/2007JC004403, 2008.

Andrews, S., Nover, D., and Schladow, S. G.: Using laser diffraction data to obtain accurate particle size distributions: The role of particle composition, Limnol. Oceanogr.-Meth. 8, 507-526. https://doi.org/10.4319/lom.2010.8.507, 2010.

Babin, M. and Stramski, D.: Variations in the massspecific absorption coefficient of mineral particles suspended in water, Limnol. Oceanogr., 49, 756-767, https://doi.org/10.4319/lo.2004.49.3.0756, 2004.

Babin, M., Therriault, J. C., Legendre, L., and Condal, A.: Variations in the specific absorption coefficient for natural phytoplankton assemblages: Impact on estimates of primary production, Limnol. Oceanogr., 38, 154-177, https://doi.org/10.4319/lo.1993.38.1.0154, 1993.

Babin, M., Stramski D., Ferrari G. M., Claustre H., Bricaud, A., Obolensky, G., and Hoepffner N.: Variations in the light absorption coefficients of phytoplankton, nonalgal particles, and dissolved organic matter in coastal waters around Europe, J. Geophys. Res., 108, 3211, https://doi.org/10.1029/2001JC000882, 2003.

Barillé-Boyer, A. L., Barillé, L., Massé, H., Razet, D., and Héral, M: Correction for particulate organic matter as estimated by loss on ignition in estuarine ecosystems, Estuar. Coast. Shelf S., 58, https://doi.org/10.1016/S0272-7714(03)00069-6, 147-153, 2003.

Binding, C. E., Bowers, D. G., and Mitchelson-Jacob, E. G.: Estimating suspended sediment concentrations from ocean colour measurements in moderately turbid waters; the impact of variable particle scattering properties, Remote Sens. Environ., 94, 373-383, https://doi.org/10.1016/j.rse.2004.11.002, 2005.

Boss, E., Twardowski, M. S., and Herring, S.: Shape of the particulate beam attenuation spectrum and its relation to the size distribution of oceanic particles, Appl. Optics, 40, 4885-4893, https://doi.org/10.1364/AO.40.004885, 2001.

Boss, E., Slade, H., Behrenfeld, M., and Dall'Olmo, G.: Acceptance angle effects on the beam attenuation in the ocean, Opt. Express, 17, 1535-1550, https://doi.org/10.1364/OE.17.001535, 2009.

Boss, E., Picheral, M., Leeuwa, T., Chase, A., Karsenti, E., Gorsky, G., Taylor, L., Slade, W., Ras, J., and Claustre, H.: The characteristics of particulate absorption, scattering and attenuation coefficients in the surface ocean; Contribution of the Tara Oceans expedition, Methods in Oceanography, 7, 52-62, https://doi.org/10.1016/j.mio.201311.002, 2013.

Bowers, D. G. and Binding, C. E.: The optical properties of mineral suspended particles: A review and synthesis, Estuar. Coast. Shelf 
S., 67, 219-230, https://doi.org/10.1016/j.ecss.2005.11.010, 2006.

Bowers, D. G., Harker, G. E. L., and Stephan, B.: Absorption spectra of inorganic particles in the Irish Sea and their relevance to remote sensing of chlorophyll, Int. J. Remote Sens., 17, 24492460, https://doi.org/10.1080/01431169608948782, 1996.

Bowers, D. G., Braithwaite, K. M., Nimmo-Smith, W. A. M., and Graham, G. W.: Light scattering by particles suspended in the sea: The role of particle size and density, Cont. Shelf Res., 29, 1748-1755, https://doi.org/10.1016/j.csr.2009.06.004, 2009.

Bricaud, A. and Stramski, D.: Spectral absorption coefficients of living phytoplankton and nonalgal biogenous matter: A comparison between Peru upwelling area and the Sargasso Sea, Limnol. Oceanogr., 35, 562-582, https://doi.org/10.4319/lo.1990.35.3.0562, 1990.

Chanut, J. P. and Poulet, S. A.: Short-term variability of the size spectra of suspended particles in a rapidly changing environment, Estuar. Coast. Shelf S., 15, 497-513, https://doi.org/10.1016/0272-7714(82)90003-8, 1982.

Dalu, T., Richoux, N. B., and Froneman, P. W.: Nature and source of suspended particulate matter and detritus along an austral temperate river-estuary continuum, assessed using stable isotope analysis, Hydrobiologia, 767, 95-110, https://doi.org/10.1007/s10750-015-2480-1, 2016.

D'Anglejan, B. F. and Smith, E. C.: Distribution, Transport, and Composition of Suspended Matter in the St. Lawrence Estuary, Can. J. Earth Sci., 10, 1380-1396, https://doi.org/10.1139/e73128, 1973.

Deflandre B., Mucci, A., Gagne, J. P., Guignard, C., and Sundby, B.: Early diagenetic processes in coastal marine sediments disturbed by a catastrophic sedimentation event, Geochim. Cosmochim. Ac., 66, 2547-2558, https://doi.org/10.1016/S00167037(02)00861-X, 2002.

Devlin, M. J., Barry, J., Mills, D. K., Gowen, R. J., Foden, J., Sivyer, D., and Tett, P.: Relationships between suspended particulate material, light attenuation and Secchi depth in UK marine waters, Estuar. Coast. Res. Shelf S., 79, 429-439, https://doi.org/10.1016/j.ecss.2008.04.024, 2008.

Doxaran, D., Froidefond, J. M., Lavender, S., and Castaing, P.: Spectral signature of highly turbid waters: Application with SPOT data to quantify suspended particulate matter concentrations, Remote Sens. Environ., 81, 149-161, https://doi.org/10.1016/S0034-4257(01)00341-8, 2002.

Doxaran, D., Ruddick, K., McKee, D., Gentili, B., Tailliez, D., Chami, M., and Babin, M.: Spectral variation of light scattering by marine paticles in coastal waters, from visible to near infrared, Limnol. Oceanogr., 54, 1257-1271, https://doi.org/10.4319/1o.2009.54.4.1257, 2009.

D'Sa, E. J. and Ko, D. S.: Short-term influences on suspended particulate matter distribution in the Northern Gulf of Mexico: Satellite and model observations, Sensors, 8, 4249-4264, https://doi.org/10.3390/s8074249, 2008.

D'Sa, E. J., Miller R. L., and Del Castillo, C.: Bio-optical properties and ocean color algorithms for coastal waters influenced by the Mississippi River during a cold front, Appl. Optics, 45, 7410 7428, https://doi.org/10.1364/AO.45.007410, 2006.

Duysens, L. N.: The flattening of the absorption spectrum of suspensions, as compared to that of solutions, Biochim. Biophys. Acta., 1, 1-12, ISSN: 0006-3002, 1956.
Eleveld, M. A., van der Wal, D., and van Kessel, T.: Estuarine suspended particulate matter concentrations from sunsynchronous satellite remote sensing:Tidal and meteorological effects and biases, Remote Sens. Environ., 143, 2014-215, https://doi.org/10.1016/j.rse.2013.12.019, 2014.

Estapa, M. L., Boss, E., Mayer, L. M., and Roesler, C. S.: Role of iron and organic carbon in massspecific light absorption by particulate matter from Louisiana coastal waters, Limnol. Oceanogr., 57, 97-112, https://doi.org/10.4319/lo.2012.57.1.0097, 2012.

Gagné, H., Lajeunesse, P., St-Onge, G., and Bolduc, A.: Recent transfer of coastal sediments to the Laurentian Channel, Lower St. Lawrence Estuary (Eastern Canada), through submarine canyon and fan systems, Geo-Mar. Lett., 29, 191-200, https://doi.org/10.1007/s00367-009-0138-6, 2009.

Guinder, V. A., Popovich, C. A., and Perillo, G. M. E.: Particulate suspended matter concentrations in the Bahia Blanca Estuary, Argentina: Implication for the development of phytoplankton blooms, Estuar. Coast. Res. Shelf S., 85, 157-165, https://doi.org/10.1016/j.ecss.2009.05.022, 2009.

Larouche, P. and Boyer-Villemaire, U.: Suspended particulate matter in the St. Lawrence estuary and Gulf surface layer and development of a remote sensing algorithm, Estuar. Coast. Shelf S., 90, 241-249, https://doi.org/10.1016/j.ecss.2010.09.005, 2010.

Levasseur, M., Therriault, J.-C., and Legendre, L.: Hierarchical control of phytoplankton succession by physical factors, Mar. Ecol. Prog. Ser., 19, 211-222, https://doi.org/10.3354/meps019211, 1984.

Loisel, H., Nicolas, J. M., Sciandra, A., Stramski, D., and Poteau, A.: Spectral dependency of optical backscattering by marine particles from satellite remote sensing of the global ocean, J. Geophys. Res. Ocean., 111, 1-14, https://doi.org/10.1029/2005JC003367, 2006.

Loisel, H., Duforet, L., Dessailly, D., Chami, M., and Dubuisson, P.: Investigation of the variations in the water leaving polarized reflectance from the POLDER satellite data over two biogeochemical contrasted oceanic areas, Opt. Express, 17, 12905-12918, https://doi.org/10.1364/OE.16.012905, 2008.

Löptien, U. and Meier, H. E. M.: The influence of increasing water turbidity on the sea surface temperature in the Baltic Sea: A model sensitivity study, J. Marine Syst., 88, 323-331, https://doi.org/10.1016/j.jmarsys.2011.06.001, 2011.

Ma, H., Kim, S. D., Allen, H. E., and Cha, D. K.: Effect of copper binding by suspended particulate matter on toxicity, Environ. Toxicol. Chem. 21, 710-714, https://doi.org/10.1002/etc.5620210404, 2002.

Mayer, L. M.: Surface area control of organic carbon accumulation in continental shelf sediments, Geochim. Cosmochim. Ac., 58, 1271-1284, https://doi.org/10.1016/0016-7037(94)90381-6, 1994.

McKee, D., Piskozub, J., and Brown, I.: Scattering error corrections for in situ absorption and attenuation measurements, Opt. Express, 16, 19480-19492, https://doi.org/10.1364/OE.16.019480, 2008.

McKee, D., Piskozub, J., Röttgers, R., and Reynolds, R. A.: Evaluation and improvement of an iterative scattering correction scheme for in situ absorption and attenuation measurements, J. Atmos. Ocean. Tech., 30, ISBN: 0739-0572, https://doi.org/10.1175/JTECH-D-12-00150.1, 2013. 
Miller, R. L. and McKee, B. A.: Using MODIS Terra $250 \mathrm{~m}$ imagery to map concentrations of total suspended matter in coastal waters, Remote Sens. Environ., 93, 259-266, https://doi.org/10.1016/j.rse.2004.07.012, 2004.

Mohammadpour, G., Montes-Hugo, M. A., Stavn, R., Gagné, J. P., and Larouche, P.: Particle Composition Effects on MERIS-Derived SPM: A Case Study in the Saint Lawrence Estuary, Can. J. Remote Sens., 41, 515-524, https://doi.org/10.1080/07038992.2015.1110012, 2015.

Montes-Hugo, M. A. and Mohammadpour, G.: Biogeo-optical modeling of SPM in the St. Lawrence Estuary, Can. J. Remote Sens., 38, 197-209, https://doi.org/10.5589/m12-033, 2012.

Morel, A.: Optical properties of pure water and pure sea water, in: Optical Aspects of Oceanography, edited by: Jerlov, N. G. and Neilsen, E. S., Academic, New York, USA, 1-24, https://doi.org/10.1007/b20012, 1974.

Morel, A. and Antoine, D.: Heating Rate within the Upper Ocean in Relation to its Bio-optical State, J. Phys. Oceanogr., 24, 16521665, https://doi.org/10.1175/1520-0485, 1994.

Neukermans, G., Loisel, H., Mériaux, X., Astoreca, R., and McKee, D.: In situ variability of mass-specific beam attenuation and backscattering of marine particles with respect to particle size, density, and composition, Limnol. Oceanogr., 57, 124-144, https://doi.org/10.4319/lo.2012.57.1.0124, 2012.

Neukermans, G., Reynolds, R. A., and Stramski, D.: Optical classification and characterization of marine particle assemblages within the western Arctic Ocean, Limnol. Oceanogr., 61, 14721494, https://doi.org/10.1002/lno.10316, 2016.

Nieke, B., Reuter, R., Heuermann, R., Wang, H., Babin, M., and Therriault, J. C.: Light absorption and fluorescence properties of chromophoric dissolved organic matter (CDOM), in the St. Lawrence Estuary (Case 2 waters), Cont. Shelf Res., 17, 235252, https://doi.org/10.1016/S0278-4343(96)00034-9, 1997

Pearson, R. K.: Mining imperfect data, Dealing with contamination and incomplete records, Society for Industrial and Applied Mathematics, Philadelphia, PA, USA, 305 p., https://doi.org/10.1137/1.9780898717884, 2005.

Poulet, S., Cossa, D., and Marty, J.-C.: Combined analyses of the size spectra and biochemical composition of particles in the St. Lawrence estuary, Mar. Ecol. Prog. Ser., 30, 205-214, http: //www.jstor.org/stable/24817553, 1986.

Poulton, S. W. and Raiswell R.: Chemical and physical characteristics of iron oxides in riverine and glacial meltwater sediments, Chem. Geol., 218, 203-221, https://doi.org/10.1016/j.chemgeo.2005.01.007, 2005.

Ramalhosa, E., Pereira, E., Vale, C., Válega, M., Monterroso, P. and Duarte, A. C.: Mercury distribution in Douro estuary (Portugal), Mar. Pollut. Bull., 50, 1218-1222, https://doi.org/10.1016/j.marpolbul.2005.04.020, 2005.

Reynolds, R. A., Stramski, D., Wright, V. M., and Woźniak, S. B.: Measurements and characterization of particle size distributions in coastal waters, J. Geoph. Res., 115, C08024, https://doi.org/10.1029/2009JC005930, 2010.

Reynolds, R. A., Stramski, D., and Neukermans, G.: Optical backscattering by particles in Arctic seawater and relationships to particle mass concentration, size distribution, and bulk composition, Limnol. Oceanogr., 61, 1869-1890, https://doi.org/10.1002/lno.10341, 2016.
Risovic, D.: Two component model of the sea particle size distribution, Deep-Sea Res. Pt. I, 40, 1459-1473, 1993.

Röttgers, R., Schönfeld, W., Kipp, P. R., and Doerffer, R.: Practical test of a point-source integrating cavity absorption meter: The performance of different collector assemblies, Appl. Optics, 44, 5549-5560, https://doi.org/10.1016/0967-0637(93)90123-K, 2005.

Röttgers, R., McKee, D., and Woźniak, S. B.: Evaluation of scatter corrections for ac-9 absorption measurements in coastal waters, Methods in Oceanography, 7, 21-39, https://doi.org/10.1016/j.mio.2013.11.001, 2013.

Röttgers, R., Dupouy, C., Taylor, B. B., Bracher, A., and Woźniak, S. B.: Mass-specific light absorption coefficients of natural aquatic particles in the near-infrared spectral region, Limnol. Oceanogr., 59, 1449-1460, https://doi.org/10.4319/lo.2014.59.5.1449, 2014.

Slade, W. H. and Boss, E.: Spectral attenuation and backscattering as indicators of average particle size, Appl. Optics, 54, 72647277, https://doi.org/10.1364/AO.54.007264, 2015.

Slade, W. H., Boss, E., and Russo C.: Effects of particle aggregation and disaggregation on their inherent optical properties, Opt Express, 19, 7945-7959, https://doi.org/10.1364/OE.19.007945, 2011.

Snyder, W., Arnone, R., Davis, C. O., Goode, W., Gould, R. W., Ladner, S., Lamela, G., Rhea, W. J., Stavn, R., Sydor, M., and Weidemann, A.: Optical scattering and backscattering by organic and inorganic particulates in US coastal waters., Appl. Optics, 47, 666-677, https://doi.org/10.1364/AO.47.000666, 2008.

Spearman, C.: The Proof and Measurement of Association between two things, Am. J. Psychol., 15, https://doi.org/10.1093/ije/dyq191, 1904.

Stavn, R. H. and Richter, S. J.: Biogeo-optics: particle optical properties and the partitioning of the spectral scattering coefficient of ocean waters, Appl. Optics, 47, 2660-2679, https://doi.org/10.1364/AO.47.002660, 2008.

Stemmann, L. and Boss, E.: Plankton and Particle Size and Packaging: From Determining Optical Properties to Driving the Biological Pump, Annu. Rev. Mar. Sci., 4, 263-290, https://doi.org/10.1146/annurev-marine-120710-100853, 2012.

Strickland, J. D. H. and Parsons, T. R.: A practical handbook of seawater analysis, Fisheries Research Board Canada, Ottawa, Canada, 310 p., https://doi.org/10.1002/iroh.19700550118, 1972.

Sullivan, J. M., Twardowski, M. S., Zaneveld, J. R. V., Moore, C. M., Barnard, A. H., Donaghay, P. L. and, Rhoades, B.: Hyperspectral temperature and salt dependencies of absorption by water and heavy water in the 400-750 nm spectral range, Appl. Optics, 45, 5294-5309, https://doi.org/10.1364/AO.45.005294, 2006.

Tremblay, L. and Gagné, J. P.: Distribution and biogeochemistry of sedimentary humic substances in the St. Lawrence Estuary and the Saguenay Fjord, Québec, Org. Geochem., 38, 682-699, https://doi.org/10.1016/j.orggeochem.2006.11.003, 2007.

Tremblay, L. and Gagné, J. P.: Organic matter distribution and reactivity in the waters of a large estuarine system, Mar. Chem., 116, 1-12, https://doi.org/10.1016/j.marchem.2009.09.006, 2009.

Twardowski, M. S., Sullivan, J. M., Donaghay, P. L., and Zaneveld, J. R. V.: Microscale Quantification of the Absorption by Dissolved and Particulate Material in Coastal Waters with an ac-9, J. 
Atm. Ocean. Tech., 16, 691-707, https://doi.org/10.1175/15200426, 1999.

Twardowski, M. S., Boss, E., Macdonald, J. B., Pegau, W. S., Barnard, A. H., and Zaneveld J. R. V.: A model for estimating bulk refractive index from the optical backscattering ratio and the implications for understanding particle composition in case I and case II waters, J. Geophy. Res, 106, 14129-14142, https://doi.org/10.1029/2000JC000404, 2001.

Woźniak, S. B., Stramski, D., Stramska, M., Reynolds, R. A., Wright, V. M., Miksic, E. Y., Cichocka, M., and Cieplak, A. M.: Optical variability of seawater in relation to particle concentration, composition, and size distribution in the nearshore marine environment at Imperial Beach, California, J. Geophys. Res.-Oceans, 115, 1-19, https://doi.org/10.1029/2009JC005554, 2010.

Xi, H., Larouche, P., Tang, S., and Michel, C.: Seasonal variability of light absorption properties and water optical constituents in Hudson Bay, Canada, J. Geophys. Res.-Oceans, 118, 3087-3102, https://doi.org/10.1002/jgrc.20237, 2014.

Xie, H., Aubry C., Bélanger S., and Song G.: The dynamics of absorption coefficients of CDOM and particles in the St. Lawrence estuarine system: Biogeochemical and physical implications, Mar. Chem., 128-129, 44-56, https://doi.org/10.1016/j.marchem.2011.10.001, 2012.

Yeats, P. A.: The distribution of trace metals in ocean waters, Sci. Total Environ., 72, 131-149, https://doi.org/10.1016/00489697(88)90012-5, 1988.
Yeats, P. A. and Bewers, J. M.: Trace metals in the waters of the Saguenay Fjord, Can. J. Earth Sci., 13, 1319-1327, https://doi.org/10.1139/e76-133, 1976.

Zaneveld, J. R. V., Kitchen, J. C., and Moore, C. M.: The scattering correction error of the reflecting-tube absorption meters, Ocean Optics XII, edited by: Jaffe, J. S., International Society for Optical Engineering, SPIE proceedings, 2258, 44-58, https://doi.org/10.1117/12.190095, 1994.

Zhang, X., Huot, Y., Gray, D. J., Weidemann, A., and Rhea, W. J.: Biogeochemical origins of particles obtained from the inversion of the volume scattering function and spectral absorption in coastal waters, Biogeosciences, 10, 6029-6043, https://doi.org/10.5194/bg-10-6029-2013, 2013.

Zhang, X., Stavn, R. H., Falster, A. U., Gray, D., and Gould, R. W.: New insight into particulate mineral and organic matter in coastal ocean waters through optical inversion, Estuar. Coast. Res. Shelf S., 149, 1-12, https://doi.org/10.1016/j.ecss.2014.06.003, 2014.

Zhang, X., Stavn, R. H., Falster, A. U., Rick, J. J., Gray, D., and Gould Jr., R. W.: Size distributions of coastal ocean suspended particulate inorganic matter:Amorphous silica and clay minerals and their dynamics, Estuar., Coast. Shelf S., 243-251, https://doi.org/10.1016/j.ecss.2017.03.025, 2017. 